\title{
Three-Dimensional Analysis of Digital Models Generated from Intraoral, Extraoral, and CBCT Scanning Devices
}

\author{
Stuart J Ryan'1, Kelton Stewart ${ }^{1}$, Ahmed Ghoneima ${ }^{1-3 *}$ \\ ${ }^{1}$ Department of Orthodontics and Oral Facial Genetics, Indiana University School Dentistry, Indianapolis, IN, USA \\ ${ }^{2}$ Department of Orthodontics, Hamdan Bin Mohammed College of Dental Medicine (MBRU), Dubai, UAE \\ ${ }^{3}$ Department of Orthodontics, College of Dental Medicine, AlAzhar University, Cairo, Egypt
}

*Correspondence author: Ahmed Ghoneima, Indiana University School of Dentistry, Department of Orthodontics and Oral Facial Genetics, 1121 West Michigan Street, DS 201, Indianapolis, IN 46202, USA; Phone: 317-278-1653; Fax: 317-278-1438; Email: aghoneim@iu.edu

Received: September 06, 2019; Accepted: September 11, 2019; Published: September 17, 2019;

\begin{abstract}
Objective: To compare the intra- and inter-arch accuracy of three-dimensional (3D) digital models acquired from various orthodontic scanners, including: an intraoral scanner, an extraoral scanner, and a cone beam computed tomography (CBCT) scan compared with the original, trimmed stone models. Methods: Fifteen sets of maxillary and mandibular finished plaster models were scanned using: Carestream 3600 intraoral scanner, OrthoInsight 3D Motion View extraoral scanner, and Carestream 9300 CBCT scanner. Dolphin Imaging software was used to calculate various anatomic measurements on the digital models. Digital calipers were used to calculate the same measurements on the original plaster models for comparative purposes. Intraclass Correlation Coefficients (ICC) and pair-wise analysis of variance (ANOVA) were utilized to compare the 4 methods (original plaster models and 3 scanning methods). Results: ICC values for all intra-arch measurements between the 4 data groups were all $>0.90$. ICC values for the two inter-arch measurements (overbite and overjet) were both 0.79 . CBCT measurements were significantly smaller than the two scanned models as well as the stone models for many intra-arch parameters. On average, these differences were less than $0.5 \mathrm{~mm}$. Conclusion: Digital models produced from CBCT scans of plaster casts appear to have adequate accuracy for orthodontic treatment planning and recordkeeping. Further studies are needed to determine the clinical efficiency of appliance design, fabrication, and chairside delivery using CBCT scanning technologies.
\end{abstract}

Keywords: digital models, scanning devices, accuracy and reliability

\section{Introduction}

Historically, plaster study models have been considered the gold standard in orthodontic patients recordkeeping [1]. Study models are valuable diagnostic tools as they allow clinicians to evaluate dental crowding and occlusal contacts, perform measurements such as the Bolton discrepancy analysis, and examine hard and soft tissue structures of the dental arches. Digital study models have become increasingly popular in both private practice and academic institutions for orthodontic treatment planning purposes [2]. Reported benefits of digital models compared to traditional stone models include: improved methods of storing digital files, simplified measurements and analysis with orthodontic software, protection from damage, and ease of retrieval and exchange with collaborating professionals $[3,4]$. For these reasons, many new digital model systems have been developed and are readily available in the orthodontic marketplace today.

There are two primary scanning methods of acquiring digital models for orthodontic purposes: intraoral and extraoral (Figure 1). Historically, intraoral scanners have utilized handheld wands, which reflect laser images from tissue structures and produce threedimensional (3D) renderings using triangulation, confocal imaging, and/or accordion fringe interferometry sensors $[5,6]$. More recently, intraoral scanners have seen an improvement in overall scan times, stemming from the advancement of trinocular 3D in-motion video technology. This new approach uses laser and Light Emitting Diode (LED) emissions to obtain a high definition video recording of intraoral structures that produce a more rapid, real-time image of the target [5]. Extraoral scanners, however, utilize 3D laser surface scanning technology with rotating bases to generate a digital model file [7]. Flugge et al. [8] evaluated intraoral and extraoral scanning accuracy and found more accurate results with the extraoral scanner compared to the intraoral scanner. The authors concluded that both scanning systems, however, yielded clinically acceptable models for orthodontic treatment planning purposes [8]. In a systematic review of the accuracy of digital models compared to traditional plaster models in orthodontics, Rossini et al. [1] concluded that digital models generated from intra- and extraoral scanning systems are equally reliable when compared to stone models in terms of accuracy and reproducibility. 


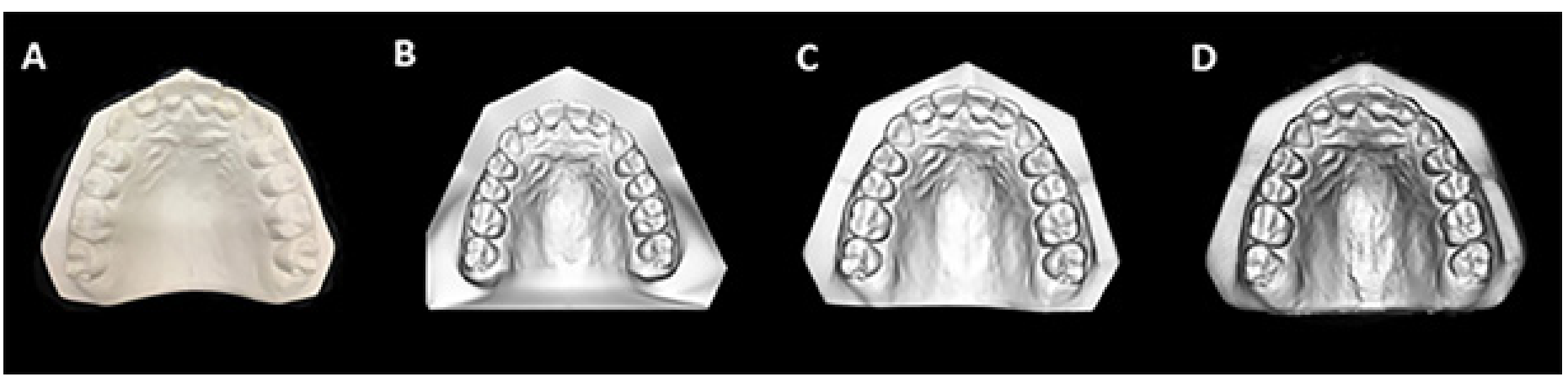

Figure 1. A. Sample image of a stone (plaster) model. B. Sample image scanned with the Carestream 3600 intraoral scanner. C. Sample image scanned with the Ortho-Insight 3D Motion View extraoral scanner. D. Sample image scanned with the Carestream 9300 CBCT machine.

The use of Cone-Beam Computed Tomography (CBCT) scans is becoming more commonplace in the orthodontic specialty [9]. CBCT has broad clinical applications, which include the scanning of the craniofacial region for orthodontic imaging of teeth, bone, and airway structures. In recent years, manufacturers have introduced the ability to use CBCT scanning of dental products including alginate impression materials. The CBCT scan can then be used to generate $3 \mathrm{D}$ renderings of the teeth and dentoalveolar structures for orthodontic records. Kim et al. [10] evaluated the accuracy of digital models derived from alginate impression materials and found that the resulting digital renderings produce clinically acceptable results for orthodontic diagnostic purposes. More recently, companies have expanded the capability and marketing of $\mathrm{CBCT}$ scanners to produce digital replications of bite registration materials and plaster and stone models (Figure 1). The aim of this study was to compare the intraand inter-arch accuracy of 3D digital models acquired from various orthodontic scanners, including: an intraoral scanner, an extraoral scanner, and a CBCT scan compared with the original trimmed stone models in order to evaluate their reliability and clinical validity. The null hypothesis tested was that no significant differences exists between measurements obtained from stone models and those generated from intraoral scanner, extraoral scanners, and CBCT scans.

\section{Methods}

In this retrospective cast analysis study, the final models of completed orthodontic cases were used as the basis for data collection. The study was approved by the Institutional Review Board at Indiana University Purdue University at Indianapolis (IRB \#1708600071). Fifteen sets of maxillary and mandibular finished plaster models were obtained from the Indiana University School of Dentistry Orthodontic Clinic archives. Inclusion criteria for the models consisted of: 1) post-treatment, finished orthodontic models, 2) trimmed to ABO standards, 3) absence of any chips or voids in the stone.

Each set of models was scanned using the: Carestream 3600 intraoral scanner (Carestream Dental ${ }^{\circledR}$, Atlanta, GA); OrthoInsight 3D Motion View (Motion View Software LLC, Chattanooga, TN) extraoral scanner, and Carestream 9300 CBCT (Carestream Dental $^{\circledR}$, Atlanta, GA). The CBCT scan utilized a $9 \mathrm{~cm}$ field of view, $0.4 \mathrm{~mm}$ voxel size, and $8.9 \mathrm{~s}$ scan time. Models were scanned resting on their trimmed bases for inter-arch measurement analyses. Each de-identified and coded scanned model was imported into the Dolphin Imaging software (version 11.9 premium; Dolphin Imaging
\& Management Solutions, Chatworth, CA). Intraoral and extraoral scanned models were uploaded under the .STL file type. CBCT models were uploaded under the .DICOM (Digital Imaging and Communications in Medicine) file type for analysis. The digitizing software features on Dolphin Imaging were used to calculate various anatomic measurements on the digital models (Table 1). Digital calipers (Pittsburgh ${ }^{\circledR}$, Camarillo, CA) with a reported accuracy of $\pm 0.02 \mathrm{~mm}$ were used to calculate the same measurements on the original plaster models for comparative purposes.

Table 1. Anatomical measurements with border specifications.

\begin{tabular}{|c|c|}
\hline Measurement (mm) & $\begin{array}{l}\text { Specifications } \\
\text { Linear distance measured from the: }\end{array}$ \\
\hline $\begin{array}{l}\text { Maxillary Intermolar } \\
\text { Width (MxIMW) }\end{array}$ & $\begin{array}{l}\text { Mesiolingual cusp tip of the right and left first } \\
\text { maxillary molars }\end{array}$ \\
\hline $\begin{array}{l}\text { Mandibular Intermolar } \\
\text { Width (MdIMW) }\end{array}$ & $\begin{array}{l}\text { Mesiolingual cusp tip of the right and left first } \\
\text { mandibular molars }\end{array}$ \\
\hline $\begin{array}{l}\text { Maxillary Intercanine } \\
\text { Width (MxICW) }\end{array}$ & Cusp tips of the maxillary left and right canines \\
\hline $\begin{array}{l}\text { Mandibular Intercanine } \\
\text { Width (MdICW) }\end{array}$ & Cusp tips of the mandibular left and right canines \\
\hline $\begin{array}{l}\text { Upper Right Central } \\
\text { Incisor Crown Height } \\
\text { (UR1H) }\end{array}$ & $\begin{array}{l}\text { Incisal edge to the gingival margin of the maxillary } \\
\text { right central incisor measured at the midpoint of the } \\
\text { mesio-distal dimension of the crown }\end{array}$ \\
\hline $\begin{array}{l}\text { Lower Right Central } \\
\text { Incisor Crown Height } \\
\text { (LR1H) }\end{array}$ & $\begin{array}{l}\text { Incisal edge to the gingival margin of the mandibular } \\
\text { right central incisor measured at the midpoint of the } \\
\text { mesio-distal dimension of the crown }\end{array}$ \\
\hline $\begin{array}{l}\text { Upper Right First } \\
\text { Premolar Crown Width } \\
\text { (UR4W) }\end{array}$ & $\begin{array}{l}\text { Mesial marginal ridge to the distal marginal ridge at the } \\
\text { midpoint of the buccal-lingual dimension of the crown }\end{array}$ \\
\hline $\begin{array}{l}\text { Lower Right First } \\
\text { Premolar Crown Width } \\
\text { (LR4W) }\end{array}$ & $\begin{array}{l}\text { Mesial marginal ridge to the distal marginal ridge at the } \\
\text { midpoint of the buccal-lingual dimension of the crown }\end{array}$ \\
\hline $\begin{array}{l}\text { Maxillary First Molar to } \\
\text { Midline (UR6Mid) }\end{array}$ & $\begin{array}{l}\text { Mesiobuccal cusp tip of the maxillary right first molar } \\
\text { to the maxillary dental midline }\end{array}$ \\
\hline $\begin{array}{l}\text { Mandibular First Molar to } \\
\text { Midline (LR6Mid) }\end{array}$ & $\begin{array}{l}\text { Mesiobuccal cusp tip of the mandibular right first molar } \\
\text { to the mandibular dental midline }\end{array}$ \\
\hline Overjet & $\begin{array}{l}\text { Mesiodistal midpoint of the facial aspect of the } \\
\text { mandibular right central incisor to the mesiodistal } \\
\text { midpoint of the lingual aspect of the maxillary right } \\
\text { central incisor in centric occlusion }\end{array}$ \\
\hline Overbite & $\begin{array}{l}\text { Mesiodistal midpoint of the incisal edge of the } \\
\text { maxillary right central incisor to the mesiodistal } \\
\text { midpoint of the incisal edge of the mandibular right } \\
\text { central incisor in centric occlusion }\end{array}$ \\
\hline
\end{tabular}


Prior to initiation of the study, the primary investigator (S.R.) performed a reliability assessment including all measurements outlined in Table 1 using 5 digital models on Dolphin Imaging, as well as 5 corresponding stone models using digital calipers. Measurements were then repeated after 10 days. Intraclass Correlation Coefficients (ICC) were calculated to statistically analyze the intrarater reliability. ICC values greater than or equal to 0.90 were considered acceptable.

For each of the parameters in Table 1, analysis of variance (ANOVA) was used to compare the 4 methods (original plaster models and 3 scanning methods). The ANOVA testing included a fixed effect for method and random effects to allow correlation among measurements from the same model; the random effects allowed the pair-wise correlations among the 4 methods to differ. Pair-wise comparisons between the methods were made using Fisher's Protected Least Significant Differences to control the overall significance level at $5 \%$. Confidence intervals for the differences between methods were also provided to examine non-significant differences for evaluation of equivalence between methods. ICCs for the measurements from the original plaster models with each of the scanning methods were also calculated.

With a sample size of 15 models, the study had a $90 \%$ power for an equivalence test comparing the scanned measurements against the original plaster model for each intra-arch parameter, assuming a 5\% significance level for each test, standard deviation of the differences between methods of $0.15 \mathrm{~mm}$, and an equivalence range of $+/-0.15 \mathrm{~mm}$.

\section{Results}

ICC values for the reliability assessment were all $\geq 0.90$. ICC values for project data showed higher reliability for intra-arch measurements compared to inter-arch measurements. Descriptive statistics outlining means and standard deviations of the measurements for each variable are outlined in Table 2. The four different model types used in the study all had ICC $>0.90$ for all eight intra-arch measurements (Table 3). Two inter-arch measurements, overbite (OB) and overjet (OJ), both had ICC values of 0.79 (Table 3).

\section{CBCT vs. Stone Models}

For the pair-wise comparison between the different model imaging methods, mean values were significantly smaller $(\mathrm{p}<.05)$ for three transverse, intra-arch measurements (MxIMW, MdIMW, and MxICW) for CBCT models compared with stone models (Table 4). Significant differences $(\mathrm{p}<.05)$ existed between CBCT models and stone models for UR1H, UR6Mid, and OB. For these three parameters, СBCT model measurements were consistently smaller than the stone measurements. MxIMW had the largest mean difference between stone and CBCT models $(-0.73 \mathrm{~mm})$. All other statistically significant differences between $\mathrm{CBCT}$ and stone models had mean differential estimates of $<0.5 \mathrm{~mm}$.

\section{CBCT vs. Extraoral Models}

CBCT models showed statistically significant differences $(\mathrm{p}<.05)$ with extraoral models for MdIMW, MxICW, UR6Mid, LR6Mid, OJ, and $\mathrm{OB}$. All measurement parameters between stone and $\mathrm{CBCT}$ models had $<0.5 \mathrm{~mm}$ average mean differences. Both vertical, intraarch parameters (central incisor crown heights) showed no significant differences between the two model sets.

\section{CBCT vs. Intraoral Models}

Statistically significant differences $(p<.05)$ were noted between CBCT models and models generated from the intraoral scanner for the following parameters: MxIMW, MxICW, MdICW, LR1H, UR6Mid, LR6Mid, OJ, OB. All measurement parameters between both scanning methods had $<0.4 \mathrm{~mm}$ average mean differences.

\section{Discussion}

While the clinical accuracy of CBCT scanning dental impressions has been previously confirmed [11], little research has been performed to evaluate the accuracy of digital replications generated from CBCT scans of stone models. Darroudi et al. [12] performed CBCT scans of plaster models for comparative purposes and observed clinically acceptable accuracy between the two model sets for orthodontic intra-arch measurements. However, the authors found significant inconsistencies between inter-arch measurements due to variability in occluding the arch models with digital wax bites. Wesemann et al. [13] compared CBCT-generated models with digital models and 3D printed models, but only examined intra-arch measurements and utilized one master model upon which all other model samples were based. The authors found the greatest accuracy with the extraoral scanner and the greatest variability with $3 \mathrm{D}$ printed models. While these studies provide preliminary insight into the potential use of CBCT scanned models, additional research is needed within the emerging digital model technologies, particularly in inter-arch model accuracy.

For digital models to serve as an adequate source of orthodontic recordkeeping, treatment planning, and/or appliance fabrication, it is essential for dimensional accuracy to remain consistent across the model types. The focus of this study was to evaluate the accuracy of digital models created using $\mathrm{CBCT}$ scanning procedures of traditional plaster models. ICC data in this study showed high reliability (ICC $>0.90)$ for all intra-arch parameters measured. These findings agree with multiple published studies, that for individual maxillary or mandibular arches, consistent dimensions appear to exist between digital models and traditional stone models $[4,10,12,13]$. Different findings were obtained, however, when the models were manually articulated and inter-arch measurements were recorded. For the inter-arch analysis, overjet and overbite showed decreased consistency between the model types, with a lower correlation coefficient (ICC=.79) for both variables. Darroudi et al. [12] digitally articulated $\mathrm{CBCT}$ models using scanned occlusal registrations (wax bites) of each patient. The authors found similar results to our study including inaccuracies with regards to inter-arch measurements of CBCT-scanned models, but found high accuracy on independentlymeasured maxillary or mandibular models [12].

In the current study, many of the intra-arch measurements were statistically smaller for CBCT models compared with stone models. This finding was consistent with previously reported CBCT model data $[14,15]$. San Jose et al. [14] attributed smaller measurements on 
Ahmed Ghoneima (2019) Three-Dimensional Analysis of Digital Models Generated from Intraoral, Extraoral, and CBCT Scanning Devices.

CBCT models to the tendency of CBCT imaging to create rounded, more indistinct proximal contact points. Our observation agreed with this notion, adding as well the lack of detailed cuspal anatomy on
CBCT models compared with stone or other digital model formats. This lack of fine detail could have resulted in a trend towards improper landmark identification for CBCT models.

Table 2. Descriptive statistics for each parameter.

\begin{tabular}{|c|c|c|c|c|c|c|}
\hline VARIABLE & Model Type & Mean & Std Dev & Std Error & Minimum & Maximum \\
\hline \multirow[t]{4}{*}{ Maxillary Intermolar Width } & $\mathrm{CBCT}$ & 40.10 & 3.03 & 0.78 & 35.17 & 45.65 \\
\hline & ExtraOral & 40.20 & 3.15 & 0.81 & 35.03 & 46.36 \\
\hline & IntraOral & 40.44 & 3.05 & 0.79 & 35.50 & 45.99 \\
\hline & Stone & 40.83 & 3.11 & 0.80 & 35.60 & 46.10 \\
\hline \multirow[t]{4}{*}{ Mandibular Intermolar Width (MdIMW) } & CBCT & 34.68 & 2.71 & 0.70 & 28.97 & 39.93 \\
\hline & ExtraOral & 34.29 & 2.79 & 0.72 & 28.16 & 39.74 \\
\hline & IntraOral & 34.52 & 2.62 & 0.68 & 28.80 & 39.50 \\
\hline & Stone & 35.02 & 2.65 & 0.68 & 29.56 & 40.11 \\
\hline \multirow[t]{4}{*}{ Maxillary Intercanine Width } & CBCT & 35.09 & 2.12 & 0.55 & 31.68 & 40.39 \\
\hline & ExtraOral & 35.45 & 2.21 & 0.57 & 32.13 & 40.64 \\
\hline & IntraOral & 35.47 & 2.16 & 0.56 & 32.06 & 40.59 \\
\hline & Stone & 35.44 & 2.04 & 0.53 & 32.41 & 40.13 \\
\hline \multirow[t]{4}{*}{ Mandibular Intercanine Width (MdICW) } & CBCT & 27.28 & 1.82 & 0.47 & 25.83 & 31.87 \\
\hline & ExtraOral & 27.51 & 1.80 & 0.46 & 25.84 & 32.45 \\
\hline & IntraOral & 27.59 & 1.90 & 0.49 & 25.46 & 32.36 \\
\hline & Stone & 27.10 & 1.71 & 0.44 & 25.29 & 31.40 \\
\hline \multirow[t]{4}{*}{ Maxillary Right Central Incisor Crown Height (UR1H) } & $\mathrm{CBCT}$ & 8.65 & 0.71 & 0.18 & 7.20 & 10.01 \\
\hline & ExtraOral & 8.62 & 0.62 & 0.16 & 7.40 & 9.86 \\
\hline & IntraOral & 8.71 & 0.63 & 0.16 & 7.34 & 10.10 \\
\hline & Stone & 8.80 & 0.74 & 0.19 & 7.23 & 10.21 \\
\hline \multirow[t]{4}{*}{ Mandibular Right Central Incisor Crown Height (LR1H) } & CBCT & 6.97 & 0.94 & 0.24 & 5.50 & 8.11 \\
\hline & ExtraOral & 7.15 & 1.16 & 0.30 & 5.59 & 8.51 \\
\hline & IntraOral & 7.20 & 1.09 & 0.28 & 5.82 & 8.49 \\
\hline & Stone & 7.10 & 1.15 & 0.30 & 5.27 & 8.54 \\
\hline \multirow[t]{4}{*}{ Maxillary First Molar to Midline (UR6Mid) } & $\mathrm{CBCT}$ & 35.67 & 3.24 & 0.84 & 29.92 & 41.75 \\
\hline & ExtraOral & 35.97 & 3.37 & 0.87 & 30.06 & 42.40 \\
\hline & IntraOral & 35.98 & 3.34 & 0.86 & 30.09 & 42.45 \\
\hline & Stone & 35.99 & 3.28 & 0.85 & 30.23 & 42.36 \\
\hline \multirow[t]{4}{*}{ Mandibular First Molar to Midline (LR6Mid) } & $\mathrm{CBCT}$ & 30.18 & 2.71 & 0.70 & 23.78 & 36.02 \\
\hline & ExtraOral & 29.87 & 2.64 & 0.68 & 23.63 & 35.48 \\
\hline & IntraOral & 29.93 & 2.67 & 0.69 & 23.73 & 35.73 \\
\hline & Stone & 30.30 & 2.67 & 0.69 & 23.91 & 35.93 \\
\hline \multirow[t]{4}{*}{ Overjet (OJ) } & CBCT & 2.53 & 0.45 & 0.12 & 1.74 & 3.46 \\
\hline & ExtraOral & 2.32 & 0.49 & 0.13 & 1.39 & 3.07 \\
\hline & IntraOral & 2.34 & 0.47 & 0.12 & 1.53 & 3.21 \\
\hline & Stone & 2.44 & 0.46 & 0.12 & 1.73 & 3.27 \\
\hline \multirow[t]{4}{*}{ Overbite (OB) } & CBCT & 1.48 & 0.56 & 0.15 & 0.60 & 2.42 \\
\hline & ExtraOral & 1.72 & 0.45 & 0.12 & 1.06 & 2.53 \\
\hline & IntraOral & 1.72 & 0.45 & 0.12 & 1.02 & 2.54 \\
\hline & Stone & 1.90 & 0.48 & 0.12 & 1.22 & 2.71 \\
\hline
\end{tabular}


Ahmed Ghoneima (2019) Three-Dimensional Analysis of Digital Models Generated from Intraoral, Extraoral, and CBCT Scanning Devices.

Table 3. Outcomes of Intraclass Correlation (ICC) tests.

\begin{tabular}{|c|c|c|c|c|c|}
\hline VARIABLE & Variance Between & Std Dev Between & Variance Within & Std Dev Within & ICC \\
\hline Maxillary Intermolar Width (MxIMW) & 9.3452 & 3.05700 & 0.2343 & 0.48400 & 0.97555 \\
\hline Mandibular Intermolar Width (MdIMW) & 7.1314 & 2.67046 & 0.1845 & 0.42958 & 0.97478 \\
\hline Maxillary Intercanine Width (MxICW) & 4.4550 & 2.11068 & 0.1144 & 0.33823 & 0.97496 \\
\hline Mandibular Intercanine Width (MdICW) & 3.1057 & 1.76230 & 0.1898 & 0.43567 & 0.94240 \\
\hline Maxillary Right Central Incisor Crown Height (UR1H) & 0.4338 & 0.65867 & 0.02690 & 0.16402 & 0.94161 \\
\hline Mandibular Right Central Incisor Crown Height (LR1H) & 1.1033 & 1.05040 & 0.08122 & 0.28499 & 0.93143 \\
\hline Maxillary First Molar to Midline (UR6Mid) & 10.8611 & 3.29562 & 0.1021 & 0.31957 & 0.99068 \\
\hline Mandibular First Molar to Midline (LR6Mid) & 7.0717 & 2.65926 & 0.1062 & 0.32591 & 0.98520 \\
\hline Overjet (OJ) & 0.1779 & 0.42179 & 0.04614 & 0.21481 & 0.79405 \\
\hline Overbite (OB) & 0.2035 & 0.45108 & 0.05475 & 0.23399 & 0.78797 \\
\hline
\end{tabular}

Table 4. ANOVA pair-wise comparison tests using Fisher's protected least significant differences.

\begin{tabular}{|c|c|c|c|c|c|c|c|}
\hline & Method 1 & Method 2 & Differential Estimate & $\begin{array}{c}\text { Standard } \\
\text { Error }\end{array}$ & $\begin{array}{c}\text { Probt } \\
\text { (p-value) }\end{array}$ & $\begin{array}{l}95 \% \text { CI } \\
\text { Lower }\end{array}$ & $\begin{array}{c}95 \% \text { CI } \\
\text { Upper }\end{array}$ \\
\hline \multirow[t]{6}{*}{ Maxillary Intermolar Width (MxIMW) } & $\mathrm{CBCT}$ & ExtraOral & -0.1073 & 0.1356 & 0.4330 & -0.3810 & 0.1663 \\
\hline & $\mathrm{CBCT}$ & IntraOral & -0.3493 & 0.1356 & 0.0136 & -0.6230 & -0.07572 \\
\hline & $\mathrm{CBCT}$ & Stone & -0.7327 & 0.1356 & $<.0001$ & -1.0063 & -0.4590 \\
\hline & ExtraOral & IntraOral & -0.2420 & 0.1356 & 0.0815 & -0.5156 & 0.03162 \\
\hline & ExtraOral & Stone & -0.6253 & 0.1356 & $<.0001$ & -0.8990 & -0.3517 \\
\hline & IntraOral & Stone & -0.3833 & 0.1356 & 0.0072 & -0.6570 & -0.1097 \\
\hline \multirow[t]{6}{*}{ Mandibular Intermolar Width (MdIMW) } & $\mathrm{CBCT}$ & ExtraOral & 0.3833 & 0.1147 & 0.0018 & 0.1519 & 0.6148 \\
\hline & $\mathrm{CBCT}$ & IntraOral & 0.1553 & 0.1147 & 0.1829 & -0.07615 & 0.3868 \\
\hline & $\mathrm{CBCT}$ & Stone & -0.3407 & 0.1147 & 0.0049 & -0.5721 & -0.1092 \\
\hline & ExtraOral & IntraOral & -0.2280 & 0.1147 & 0.0534 & -0.4595 & 0.003483 \\
\hline & ExtraOral & Stone & -0.7240 & 0.1147 & $<.0001$ & -0.9555 & -0.4925 \\
\hline & IntraOral & Stone & -0.4960 & 0.1147 & $<.0001$ & -0.7275 & -0.2645 \\
\hline \multirow[t]{6}{*}{ Maxillary Intercanine Width (MxICW) } & $\mathrm{CBCT}$ & ExtraOral & -0.3540 & 0.1082 & 0.0021 & -0.5723 & -0.1357 \\
\hline & $\mathrm{CBCT}$ & IntraOral & -0.3767 & 0.1082 & 0.0012 & -0.5950 & -0.1583 \\
\hline & $\mathrm{CBCT}$ & Stone & -0.3480 & 0.1082 & 0.0025 & -0.5663 & -0.1297 \\
\hline & ExtraOral & IntraOral & -0.02267 & 0.1082 & 0.8351 & -0.2410 & 0.1957 \\
\hline & ExtraOral & Stone & 0.006000 & 0.1082 & 0.9560 & -0.2123 & 0.2243 \\
\hline & IntraOral & Stone & 0.02867 & 0.1082 & 0.7923 & -0.1897 & 0.2470 \\
\hline \multirow[t]{6}{*}{ Mandibular Intercanine Width (MdICW) } & $\mathrm{CBCT}$ & ExtraOral & -0.2340 & 0.1414 & 0.1054 & -0.5194 & 0.05136 \\
\hline & $\mathrm{CBCT}$ & IntraOral & -0.3087 & 0.1414 & 0.0347 & -0.5940 & -0.02331 \\
\hline & $\mathrm{CBCT}$ & Stone & 0.1800 & 0.1414 & 0.2100 & -0.1054 & 0.4654 \\
\hline & ExtraOral & IntraOral & -0.07467 & 0.1414 & 0.6002 & -0.3600 & 0.2107 \\
\hline & ExtraOral & Stone & 0.4140 & 0.1414 & 0.0055 & 0.1286 & 0.6994 \\
\hline & IntraOral & Stone & 0.4887 & 0.1414 & 0.0013 & 0.2033 & 0.7740 \\
\hline
\end{tabular}


Ahmed Ghoneima (2019) Three-Dimensional Analysis of Digital Models Generated from Intraoral, Extraoral, and CBCT Scanning Devices.

\begin{tabular}{|c|c|c|c|c|c|c|c|}
\hline & Method 1 & Method 2 & Differential Estimate & $\begin{array}{l}\text { Standard } \\
\text { Error }\end{array}$ & $\begin{array}{c}\text { Probt } \\
\text { (p-value) }\end{array}$ & $\begin{array}{l}95 \% \mathrm{CI} \\
\text { Lower }\end{array}$ & $\begin{array}{l}95 \% \mathrm{CI} \\
\text { Upper }\end{array}$ \\
\hline \multirow{6}{*}{$\begin{array}{l}\text { Maxillary Right Central Incisor Crown Height } \\
\text { (UR1H) }\end{array}$} & $\mathrm{CBCT}$ & ExtraOral & 0.03733 & 0.05373 & 0.4910 & -0.07110 & 0.1458 \\
\hline & $\mathrm{CBCT}$ & IntraOral & -0.06133 & 0.05373 & 0.2601 & -0.1698 & 0.04710 \\
\hline & CBCT & Stone & -0.1500 & 0.05373 & 0.0079 & -0.2584 & -0.04157 \\
\hline & ExtraOral & IntraOral & -0.09867 & 0.05373 & 0.0734 & -0.2071 & 0.009762 \\
\hline & ExtraOral & Stone & -0.1873 & 0.05373 & 0.0012 & -0.2958 & -0.07890 \\
\hline & IntraOral & Stone & -0.08867 & 0.05373 & 0.1063 & -0.1971 & 0.01976 \\
\hline \multirow{6}{*}{$\begin{array}{c}\text { Mandibular Right Central Incisor Crown } \\
\text { Height (LR1H) }\end{array}$} & $\mathrm{CBCT}$ & ExtraOral & -0.1747 & 0.1013 & 0.0920 & -0.3791 & 0.02978 \\
\hline & $\mathrm{CBCT}$ & IntraOral & -0.2260 & 0.1013 & 0.0311 & -0.4304 & -0.02155 \\
\hline & $\mathrm{CBCT}$ & Stone & -0.1247 & 0.1013 & 0.2253 & -0.3291 & 0.07978 \\
\hline & ExtraOral & IntraOral & -0.05133 & 0.1013 & 0.6150 & -0.2558 & 0.1531 \\
\hline & ExtraOral & Stone & 0.05000 & 0.1013 & 0.6242 & -0.1544 & 0.2544 \\
\hline & IntraOral & Stone & 0.1013 & 0.1013 & 0.3229 & -0.1031 & 0.3058 \\
\hline \multirow[t]{6}{*}{ Maxillary First Molar to Midline (UR6Mid) } & $\mathrm{CBCT}$ & ExtraOral & -0.3000 & 0.1060 & 0.0071 & -0.5139 & -0.08609 \\
\hline & $\mathrm{CBCT}$ & IntraOral & -0.3047 & 0.1060 & 0.0063 & -0.5186 & -0.09076 \\
\hline & $\mathrm{CBCT}$ & Stone & -0.3140 & 0.1060 & 0.0050 & -0.5279 & -0.1001 \\
\hline & ExtraOral & IntraOral & -0.00467 & 0.1060 & 0.9651 & -0.2186 & 0.2092 \\
\hline & ExtraOral & Stone & -0.01400 & 0.1060 & 0.8956 & -0.2279 & 0.1999 \\
\hline & IntraOral & Stone & -0.00933 & 0.1060 & 0.9303 & -0.2232 & 0.2046 \\
\hline \multirow[t]{6}{*}{ Mandibular First Molar to Midline (LR6Mid) } & $\mathrm{CBCT}$ & ExtraOral & 0.3040 & 0.09686 & 0.0031 & 0.1085 & 0.4995 \\
\hline & $\mathrm{CBCT}$ & IntraOral & 0.2500 & 0.09686 & 0.0134 & 0.05452 & 0.4455 \\
\hline & $\mathrm{CBCT}$ & Stone & -0.1187 & 0.09686 & 0.2274 & -0.3141 & 0.07681 \\
\hline & ExtraOral & IntraOral & -0.05400 & 0.09686 & 0.5802 & -0.2495 & 0.1415 \\
\hline & ExtraOral & Stone & -0.4227 & 0.09686 & $<.0001$ & -0.6181 & -0.2272 \\
\hline & IntraOral & Stone & -0.3687 & 0.09686 & 0.0005 & -0.5641 & -0.1732 \\
\hline \multirow[t]{6}{*}{ Overjet (OJ) } & $\mathrm{CBCT}$ & ExtraOral & 0.2127 & 0.07229 & 0.0053 & 0.06678 & 0.3586 \\
\hline & $\mathrm{CBCT}$ & IntraOral & 0.1927 & 0.07229 & 0.0109 & 0.04678 & 0.3386 \\
\hline & CBCT & Stone & 0.09667 & 0.07229 & 0.1883 & -0.04922 & 0.2426 \\
\hline & ExtraOral & IntraOral & -0.02000 & 0.07229 & 0.7834 & -0.1659 & 0.1259 \\
\hline & ExtraOral & Stone & -0.1160 & 0.07229 & 0.1161 & -0.2619 & 0.02988 \\
\hline & IntraOral & Stone & -0.09600 & 0.07229 & 0.1913 & -0.2419 & 0.04988 \\
\hline \multirow[t]{6}{*}{ Overbite (OB) } & СBCT & ExtraOral & -0.2340 & 0.06055 & 0.0004 & -0.3562 & -0.1118 \\
\hline & $\mathrm{CBCT}$ & IntraOral & -0.2433 & 0.06055 & 0.0002 & -0.3655 & -0.1211 \\
\hline & $\mathrm{CBCT}$ & Stone & -0.4153 & 0.06055 & $<.0001$ & -0.5375 & -0.2931 \\
\hline & ExtraOral & IntraOral & -0.00933 & 0.06055 & 0.8782 & -0.1315 & 0.1129 \\
\hline & ExtraOral & Stone & -0.1813 & 0.06055 & 0.0046 & -0.3035 & -0.05913 \\
\hline & IntraOral & Stone & -0.1720 & 0.06055 & 0.0069 & -0.2942 & -0.04980 \\
\hline
\end{tabular}


No significant differences were noted between intraoral and extraoral scanned models for any parameter. The authors felt that occlusal anatomy was most detailed on these two particular model sets. Additionally, both of these model sets were measured using Dolphin software, i.e. no manual digital caliper usage. This improvement in cuspal anatomy, coupled with the digital measuring technique, could have resulted in improved consistency between the model sets.

While statistically significant differences were reported between many stone model and CBCT model parameters, it is important to evaluate the differential estimates of these comparisons. All parameters other than maxillary intermolar width had differential estimates of $<0.5 \mathrm{~mm}$. This finding is of clinical significance, as a discrepancy of $<0.5 \mathrm{~mm}$ could provide clinically ample model sets for treatment planning and diagnostic recordkeeping. The largest discrepancy was noted for maxillary intermolar width, which had a differential estimate of $-0.73 \mathrm{~mm}$. This could be attributed to the aforementioned lack of cuspal anatomy and rounded edges of CBCT models. Maxillary intermolar width was also the largest linear parameter measured in this study, so a slightly increased discrepancy between the models for this variable was not a surprising finding. To further analyze accuracy between digital model sets, additional studies should incorporate superimpositions of CBCT scans over other digitally scanned models with color mapping to localize discrepancies between the various scanning modalities. Furthermore, additional studies should evaluate whether the discrepancies observed between stone and СBCT models are significant enough to impact appliance delivery and overall clinical efficiency.

\section{Conclusion}

Digital models fabricated from CBCT scans of plaster casts appear to have adequate accuracy for orthodontic treatment planning and recordkeeping. Further studies are needed to determine the clinical efficiency of appliance design and chairside delivery using СBCT scanning.

\section{References}

1. Rossini G, Parrini S, Castroflorio T, Deregibus A, Debernardi CL (2016) Diagnostic accuracy and measurement sensitivity of digital models for orthodontic purposes: A systematic review. American Journal of Orthodontics and Dentofacial Orthopedics 149: 161-70.

2. Shastry S, Park JH (2014) Evaluation of the use of digital study models in postgraduate orthodontic programs in the United States and Canada. The Angle Orthodontist 84: 62-67.

3. Wiranto MG, Engelbrecht WP, Tutein Nolthenius HE, van der Meer WJ, Ren Y. (2013) Validity, reliability, and reproducibility of linear measurements on digital models obtained from intraoral and cone-beam computed tomography scans of alginate impressions. American Journal of Orthodontics and Dentofacial Orthopedics 143: 140-47.

4. Fleming PS, Marinho V, Johal A. (2011) Orthodontic measurements on digital study models compared with plaster models: a systematic review. Orthodontics Craniofacial Research 14: 1-16.

5. Kravitz ND, Groth C, Jones PE, Graham JW, Redmond WR (2014) Intraoral digital scanners. Journal of Clinical Orthodontics 48: 337-47.

6. Garino F, Garino GB, Castroflorio T (2014) The iTero intraoral scanner in Invisalign treatment: a two-year report. Journal of Clinical Orthodontics 48: 98-106.

7. Thiruvenkatachari B (2009) Measuring 3-dimensional tooth movement with a 3-dimensional surface laser scanner. American Journal of Orthodontics and Dentofacial Orthopedics 135: 480-85.

8. Flugge T, Schlager S, Nelson K, Nahles S, Metzger M. (2013) Precision of intraoral digital dental impressions with iTero and extraoral digitzation with the iTero and a model scanner. American Journal of Orthodontics and Dentofacial Orthopedics 144: 471-8.
9. Detterbeck A (2016) MRI vs. CT for orthodontic applications: comparison of two MRI protocols and three CT (multislice, cone-beam, industrial) technologies. Journal of Orofacial Orthopedics 77: 251-261.

10. Kim J, Heo G, Lagravère MO. (2014) Accuracy of laser-scanned models compared to plaster models and cone-beam computed tomography. The Angle Orthodontist 84: 443-50.

11. Lee SM, Hou Y, Cho JH, Hwang HS (2016) Dimensional accuracy of digital dental models from cone-beam computed tomography scans of alginate impressions according to time elapsed after the impressions. American Journal of Orthodontics and Dentofacial Orthopedics 149: 287-94.

12. Darroudi AM (2017) Accuracy of a computed tomography scanning procedure to manufacture digital models. American Journal of Orthodontics and Dentofacial Orthopedics 151: 995-1003.

13. Wesemann C, Muallah J, James M, Bumann A (2017) Accuracy and efficiency of full-arch digitalization and 3D printing: A comparison between desktop model scanners, an intraoral scanner, a CBCT model scan, and stereolithographic 3D printing. Quintessence International 48: 41-50.

14. San Jose V (2017) Dental measurements and Bolton index reliability and accuracy obtained from 2D digital, 3D segmented CBCT, and 3d intraoral laser scanner. Journal of Clinical and Experimental Dentistry 9: 1466-73.

15. Kau CK. (2010) Evaluation of CBCT Digital Models and Traditional Models Using the Little's Index. The Angle Orthodontist 80: 435-439.

\section{Citation:}

Ryan SJ, Stewart K, Ghoneima A (2019) Three-Dimensional Analysis of Digital Models Generated from Intraoral, Extraoral, and CBCT Scanning Devices. J Dent Maxillofacial Res Volume 2(4): 1-7. 